\title{
Association between chronic kidney disease and physical activity level in patients with ischemic heart disease
}

Ryota Matsuzawa ${ }^{1}$, Takashi Masuda ${ }^{2,3^{*}}$, Kentaro Kamiya ${ }^{1}$, Nobuaki Hamazaki ${ }^{1,3}$, Kohei Nozaki $^{1}$, Shinya Tanaka ${ }^{3}$, Emi Maekawa ${ }^{4}$ and Junya Ako $^{3,4}$

\begin{abstract}
Background: Although it is believed that chronic kidney disease (CKD) in patients with ischemic heart disease (IHD) negatively affects physical activity after discharge, its actual influence on the physical activity of patients with IHD remains unclear. This study aimed to investigate the association between CKD and the acquirement of appropriate physical activity after hospital discharge in patients with IHD.

Methods: Subjects were 245 patients with IHD (65 111 years, 203 males) admitted to Kitasato University Hospital from July 2007 to January 2014 due to unstable angina pectoris or acute myocardial infarction. Appropriate physical activity was defined according to the American Heart Association/the American College of Cardiology guidelines, which recommend $\geq 150 \mathrm{~min} /$ week of moderate-to-vigorous activity. We assessed intervention for IHD, comorbidities, smoking habits, serum high-sensitivity C-reactive protein, estimated glomerular filtration rate (eGFR), left ventricular ejection fraction, duration of hospital stay, 6-min walk distance during hospitalization, and physical activity 3 months after discharge. Patients with eGFR $\geq 60 \mathrm{~mL} / \mathrm{min} / 1.73 \mathrm{~m}^{2}$ and $15 \leq \mathrm{eGFR}<60 \mathrm{~mL} / \mathrm{min} / 1.73 \mathrm{~m}^{2}$ were diagnosed with stage G1-G2 CKD and stage G3-G4 CKD, respectively.

Results: Only 87 patients (35.5\%) achieved appropriate levels of physical activity. Stepwise multivariate logistic regression analysis identified stage G3-G4 CKD (odds ratio, 1.91; $95 \% \mathrm{Cl}, 1.02-3.55 ; P=0.04$ ) and a 6 -min walk distance $<400 \mathrm{~m}$ (odds ratio, $17.8 ; 95 \% \mathrm{Cl}, 4.16-76.6 ; P<0.001)$ as significant independent factors that hinder acquiring appropriate physical activity.
\end{abstract}

Conclusions: Stage G3-G4 CKD was associated with poor acquirement of appropriate physical activity after hospital discharge in patients with IHD.

Keywords: CKD, Ischemic heart disease, Coronary artery disease, Physical activity

\section{Background}

Increased physical activity reduces cardiovascular mortality risk in general populations [1]. Furthermore, recent meta-analyses revealed that the physically active had a 20-50\% less risk of coronary heart disease than the physically inactive $[2,3]$. The American Heart Association (AHA) presented seven impact goals for maintaining healthy cardiovascular conditions in all adults that

\footnotetext{
* Correspondence: tak9999@med.kitasato-u.ac.jp

${ }^{2}$ Department of Rehabilitation, School of Allied Health Sciences, Kitasato

University, 1-15-1 Kitasato, Sagamihara, Kanagawa 252-0373, Japan

${ }^{3}$ Department of Cardio-Angiology, Graduate School of Medical Sciences,

Kitasato University, Sagamihara, Japan

Full list of author information is available at the end of the article
}

included a physically active lifestyle and management of cholesterol, blood pressure, blood sugar, smoking status, weight, and diet [4]. The lifestyle management guidelines published by the AHA and the American College of Cardiology (ACC) in 2013 stated that physical activity of moderate-to-vigorous intensity for at least $150 \mathrm{~min}$ a week is appropriate for obtaining a variety of health benefits [5]. In addition, maintaining a physically active lifestyle is important for both primary and secondary prevention of ischemic heart disease (IHD). Many patients with IHD, however, tend to have poor physical activity after hospital discharge [6]. Increased physical activity also provides a large variety of health benefits to 
chronic kidney disease (CKD) patients [7, 8]. However, previous studies reported that the majority of CKD patients were physically inactive in their daily living $[7,9,10]$. Although it is believed that CKD in patients with IHD negatively affects physical activity after discharge, its actual influence on the physical activity of patients with IHD remains unclear.

The purpose of this study was to investigate the association between CKD and the acquirement of appropriate physical activity after hospital discharge in patients with IHD.

\section{Methods}

\section{Study population}

This study was approved by the Kitasato University Hospital Research Ethic Committee. After receiving an explanation of the study purpose and protocol, all patients gave their informed consent.

Subjects were 245 patients with IHD admitted to Kitasato University Hospital from July 2007 to January 2014 due to unstable angina pectoris or acute myocardial infarction and underwent cardiac rehabilitation during hospitalization. The patients included 203 men and 42 women (mean age, 65 years; range, 31 to 86 years). Of the 245 patients, 54 (22.0\%) received coronary artery bypass graft surgery and 191 (78.0\%) received percutaneous coronary intervention. All patients were successfully treated for coronary artery reperfusion and experienced no myocardial ischemia, as determined by electrocardiograph changes or chest pain after hospital discharge. Patients were excluded from the study if they received maintenance hemodialysis therapy (stage 5D) or needed any assistance with walking, occurred with heart failure, and refused to be measured the physical activity at 3 months after hospital discharge. Because the health benefits of increased physical activity are unclear in patients with stage G5 CKD who are not on hemodialysis and medical staffs did not educate and enhance them to participate in exercise aggressively in contrast to patients with stages G1-G4 CKD and 5D, the patients with stage G5 CKD were also excluded.

\section{Clinical characteristics}

Patient information on age, gender, height, employment, intervention for IHD, smoking habits, and comorbid conditions such as cerebrovascular disease, peripheral arterial disease, orthopedic disorder, or diabetes mellitus were collected from medical records or by interview at study entry. Body weight, body mass index, left ventricular ejection fraction on an echocardiogram, anklebrachial index, and duration of hospital stay, were determined at hospital discharge. We measured blood hemoglobin and serum levels of albumin, creatine kinase, and high-sensitivity C-reactive protein and assessed the estimated glomerular filtration rate (eGFR) after admission. The parameter of eGFR was re-assessed at 3 months after hospital discharge, and the difference in eGFR between at baseline and 3 months was calculated. Peak creatine kinase levels in patients with acute myocardial infarction were also confirmed during hospitalization. In patients with diabetes, HbA1c levels were investigated at hospital discharge. Peripheral arterial disease was assessed using an ankle-brachial index (Form PWV/ABI, Omron Colin, Tokyo, Japan). Patients with an eGFR $\geq 60 \mathrm{~mL} / \mathrm{min} / 1.73 \mathrm{~m}^{2}, 15-60 \mathrm{~mL} / \mathrm{min} /$ $1.73 \mathrm{~m}^{2}$, and $<15 \mathrm{~mL} / \mathrm{min} / 1.73 \mathrm{~m}^{2}$ were diagnosed with stage G1-G2 CKD, stage G3-G4 CKD, and stage G5 CKD, respectively.

\section{Exercise capacity}

Six-minute walk distance was measured at hospital discharge and 3 months as an indicator of exercise capacity, in accordance with guidelines established by the American Thoracic Society [11]. The difference in 6-min walk distance between at baseline and 3 months was calculated. After patients received a detailed explanation of the procedure from a physical therapist, they were instructed to walk as fast and long as possible along a 30-m walkway marked at $1-\mathrm{m}$ intervals. Patients were allowed to stop and rest or reduce their walking speed if they felt shortness of breath or fatigue. The physical therapist encouraged patients during the test (e.g., "you are doing well", "keep up the good work"). Measurement was suspended if patients experienced chest pain, dyspnea, leg cramps, hyperhidrosis, cyanosis, or facial pallor during the test. The Society of Sarcopenia, Cachexia and Wasting Disorders defined individuals with 6-min walk distance $<400 \mathrm{~m}$ as having reduced physical activity [12]. In the present study, 6-min walk distance $\geq 400 \mathrm{~m}$ was adopted as an appropriate level of exercise capacity for patients with IHD.

\section{Physical activity}

Physical activity was assessed using an accelerometer (Lifecorder; Suzuken, Nagoya, Japan) 3 months after hospital discharge. The accelerometer was worn at the waist for 7 days, except during bathing and sleeping, to record vertical acceleration of the body and number of steps. Instrument accuracy and reliability was confirmed in previous study [13]. Vertical vector magnitude was analyzed every $2 \mathrm{~min}$ and then digitally divided into 11 grades of $0,0.5$, and 1.0 to 9.0 , with a lower grade indicating lower intensity of physical activity. Briefly, grades $<3.0,4.0-6.0$, and $>7.0$ corresponded to physical activity at light (1.8-2.9 Mets), moderate (3.6-5.2 Mets), and vigorous (>6.1 Mets) intensity, respectively [14]. According to the AHA/ACC guidelines, adults should engage in physical activity at moderate-to-vigorous intensity, 
such as brisk walking, for at least $150 \mathrm{~min}$ a week [5]. To evaluate this activity, the time patients spent moving at moderate-to-vigorous intensity per week was aggregated. An aggregated time $\geq 150 \mathrm{~min} /$ week was defined as appropriate physical activity. In addition to time spent moving per week, the number of steps per day was also counted for physical activity.

\section{Statistical analysis}

The chi-square test or unpaired $t$ test was used to compare differences in patient characteristics, 6-min walk distance, and physical activity between patients with stage G1-G2 CKD and patients with stage G3-G4 CKD. In comparison of physical activity levels between the two groups, the patients were stratified by age $(<65$ years or $\geq 65$ years. Additionally, after we selected the active patients with higher frequency of attendance to ambulant cardiac rehabilitation ( $\geq 1.1$ time per week) [15] from our study participants, we evaluated the differences in patient characteristics, renal function, and exercise capacity of the active participants. To evaluate whether CKD disrupted acquirement of appropriate physical activity after hospital discharge, a stepwise multivariate logistic regression analysis was performed using CKD stage, age, sex, body mass index, employment, intervention for IHD, comorbid conditions, smoking habits, blood hemoglobin, serum albumin and high-sensitivity $C$-reactive protein, left ventricular ejection fraction, duration of hospital stay and 6-min walk distance as exploratory variables, with physical activity as a dependent variable. Data are presented as mean \pm standard deviation or a percentage, with a $P$ value less than 0.05 considered statistically significant. Analyses were performed using SPSS software, version 22.0 (IBM Corporation, Armonk, NY, USA).

\section{Results}

\section{Clinical characteristics and exercise capacity}

Clinical characteristics and exercise capacity are summarized in Table 1. Patients with stage G3-G4 CKD were significantly older compared to those with stage G1-G2 CKD $(P<0.001)$, while the ratio of patients who were unemployed or had a smoking history were significantly higher $(P=0.002$ and $P=0.007$, respectively). Blood hemoglobin, eGFR, and left ventricular ejection fraction were significantly lower in patients with stage G3-G4 CKD $(P=0.008, P<0.001$, and $P=0.001$, respectively), and their duration at the hospital was significantly longer $(P=0.04)$. The 6 -min walk distance was $465 \pm 101 \mathrm{~m}$ for all patients, $470 \pm 104 \mathrm{~m}$ for patients with stage G1G2 CKD, and $459 \pm 98 \mathrm{~m}$ for patients with stage G3-G4 CKD. There was no significant difference in 6-min walk distance between patients with stage G1-G2 CKD and those with stage G3-G4 CKD.

\section{Physical activity}

Physical activity after hospital discharge is shown in Fig. 1. The number of steps and moderate-tovigorous physical activity were significantly lower in patients with stage G3-G4 CKD than in those with stage G1-G2 CKD $(P=0.01$ and $P<0.001$, respectively). Of the 245 patients, 87 patients (35.5\%) acquired appropriate physical activity, that is, 29 (25.4\%) among patients with stage G3-G4 CKD and $58(44.3 \%)$ among those with stage G1-G2 CKD. The ratio was significantly lower in stage G3-G4 CKD than in stage G1-G2 CKD $(P=0.002)$. Although the significant associations of CKD stage with acquirement rate of appropriate physical activity and moderate-to-vigorous physical activity were seen in patients aged 65 years and older, there was no association between CKD stage and physical activity levels in patients aged 64 years or younger.

\section{Logistic regression analyses}

The results of univariate and multivariate logistic regression analyses are presented in Table 2 . In the univariate logistic regression analysis, stage G3-G4 CKD, an older age, female gender, unemployment, lower blood hemoglobin and albumin levels, longer duration of hospital stay, and a 6-min walk distance $<400 \mathrm{~m}$ significantly contributed to reduced physical activity. Stepwise multivariate analysis identified stage G3-G4 CKD (odds ratio, 1.91; 95\% confidence interval, 1.02-3.55; $P=0.04$ ) and a 6 -min walk distance $<400 \mathrm{~m}$ (odds ratio, 17.8; 95\% confidence interval, 4.16-76.6; $P<0.001)$ as significant independent factors that hinder acquiring appropriate physical activity.

\section{Changes in renal function and exercise capacity}

Table 3 shows change in renal function and exercise capacity between patients with stage G1-G2 CKD and G3-G4 CKD. In patients with stages G3-G4, eGFR was significantly increased after 3 months $(P=0.03)$. On the other hand, $\Delta 6$-min walk distance was significantly higher in patients with stage G1-G2 CKD than stage G3-G4 CKD, although clinical significant improvement of 6-min walk distance was seen in patients with stage G3-G4 CKD.

Table 4 summarizes baseline characteristics and change in renal function and exercise capacity from hospital discharge to 3 months in active and nonactive participants. In active participants, eGFR and 6-min walk distance improved, (eGFR $58.8 \pm 20.6$ to $61.8 \pm 17.2 \mathrm{~mL} / \mathrm{min} / 1.73 \mathrm{~m}^{2}, \quad \Delta+4.77 \mathrm{~mL} / \mathrm{min} /$ $1.73 \mathrm{~m}^{2}, 6$-min walk distance $451.8 \pm 85.3$ to $511.9 \pm$ $88.1 \mathrm{~m}, \Delta+60.1 \mathrm{~m})$. 
Table 1 Clinical characteristics and exercise capacity

\begin{tabular}{|c|c|c|c|c|}
\hline & $\begin{array}{l}\text { All patients } \\
(n=245)\end{array}$ & $\begin{array}{l}\text { Stage G1-G2 } \\
\text { CKD }(n=131)\end{array}$ & $\begin{array}{l}\text { Stage G3-G4 } \\
\text { CKD }(n=114)\end{array}$ & $P$ \\
\hline Age (years) & $64.6 \pm 10.5$ & $61.6 \pm 11.0$ & $68.0 \pm 8.9$ & $<0.001$ \\
\hline Gender (\% male) & 82.9 & 81.7 & 84.2 & 0.60 \\
\hline Height (m) & $1.6 \pm 0.1$ & $1.64 \pm 0.08$ & $1.62 \pm 0.08$ & 0.13 \\
\hline Weight (kg) & $63.3 \pm 11.5$ & $63.7 \pm 12.2$ & $63.0 \pm 10.6$ & 0.64 \\
\hline Body mass index $\left(\mathrm{kg} / \mathrm{m}^{2}\right)$ & $23.8 \pm 3.3$ & $23.7 \pm 3.4$ & $23.9 \pm 3.1$ & 0.54 \\
\hline Unemployed (\%) & 50.2 & 40.5 & 60.5 & 0.002 \\
\hline Intervention for IHD & & & & 0.79 \\
\hline CABG (\%) & 22.0 & 21.4 & 22.8 & \\
\hline $\mathrm{PCl}(\%)$ & 78.0 & 78.6 & 77.2 & \\
\hline \multicolumn{5}{|l|}{ Comorbidities (\%) } \\
\hline Cerebrovascular disease & 8.6 & 6.9 & 10.5 & 0.31 \\
\hline Orthopedic disorder & 17.6 & 19.1 & 15.8 & 0.50 \\
\hline Diabetes mellitus & 39.6 & 34.4 & 45.6 & 0.07 \\
\hline Smoking (\%) & & & & 0.007 \\
\hline Current & 36.1 & 43.8 & 27.2 & \\
\hline Former & 36.9 & 28.5 & 46.5 & \\
\hline Never & 27.0 & 27.7 & 26.3 & \\
\hline \multicolumn{5}{|l|}{ Laboratory data } \\
\hline Hemoglobin (g/dL) & $12.9 \pm 1.72$ & $13.1 \pm 1.62$ & $12.6 \pm 1.80$ & 0.008 \\
\hline Peak creatine kinase (IU/L) & $2841 \pm 2583$ & $2871 \pm 2460$ & $2778 \pm 2743$ & 0.83 \\
\hline Albumin (g/dL) & $3.9 \pm 0.4$ & $4.0 \pm 0.4$ & $3.9 \pm 0.4$ & 0.15 \\
\hline High-sensitive CRP (mg/dL) & $0.76 \pm 0.33$ & $0.80 \pm 1.19$ & $0.73 \pm 1.24$ & 0.67 \\
\hline eGFR $\left(\mathrm{mL} / \mathrm{min} / 1.73 \mathrm{~m}^{2}\right)$ & $61.5 \pm 18.4$ & $74.5 \pm 11.5$ & $46.5 \pm 12.5$ & 0.001 \\
\hline $\mathrm{HbA1c}(\%)$ & $6.03 \pm 1.17$ & $6.02 \pm 1.29$ & $6.06 \pm 1.07$ & 0.87 \\
\hline Left ventricular ejection fraction (\%) & $50.7 \pm 13.3$ & $53.4 \pm 11.4$ & $47.5 \pm 14.7$ & 0.001 \\
\hline Ankle-brachial index & $1.08 \pm 0.12$ & $1.09 \pm 0.12$ & $1.08 \pm 0.13$ & 0.68 \\
\hline Duration of hospital stay (days) & $26.8 \pm 17.2$ & $24.8 \pm 14.4$ & $29.2 \pm 19.7$ & 0.04 \\
\hline 6-min walk distance (m) & $464.6 \pm 101.1$ & $470.3 \pm 104.2$ & $459.0 \pm 97.8$ & 0.43 \\
\hline
\end{tabular}

Values are expressed as mean \pm standard deviation or percentage

$C A B G$ coronary artery bypass graft, CKD chronic kidney disease, CRP C-reactive protein, eGFR estimated glomerular filtration rate, IHD ischemic heart disease, $\mathrm{PCl}$ percutaneous coronary intervention

\section{Discussion}

The present study demonstrated that CKD in patients with IHD prevented the achievement of appropriate physical activity after hospital discharge. In particular, having stage G3-G4 CKD was a significant independent limiting factor. To our knowledge, this is the first study showing the association between CKD and objectively measured physical activity level in patients with IHD.

Many studies have reported that increased physical activity reduces cardiovascular risk and all-cause mortality risk in general populations [1-3] or in patients with end-stage renal disease [16]. Wannamethee et al. also reported that maintaining a physically active lifestyle could decrease the risk of all-cause mortality in patients with
IHD [17]. Although it was formerly believed that increasing physical activity worsened renal function in patients with CKD via reduced renal blood flow, recent studies have shown beneficial effects on not only exercise capacity $[18,19]$ but also renal function $[8,15]$. In our data, the patients with higher frequency of attendance to our cardiac rehabilitation program experienced an improvement of renal function as previously reported [15]. A prospective cohort study demonstrated that increasing physical activity delayed the deterioration of renal function in patients with stage G3-G4 CKD [8]. Furthermore, recent study reported that an aerobic exercise program was safely performed by patients with IHD who have CKD and improved their eGFR [15]. 


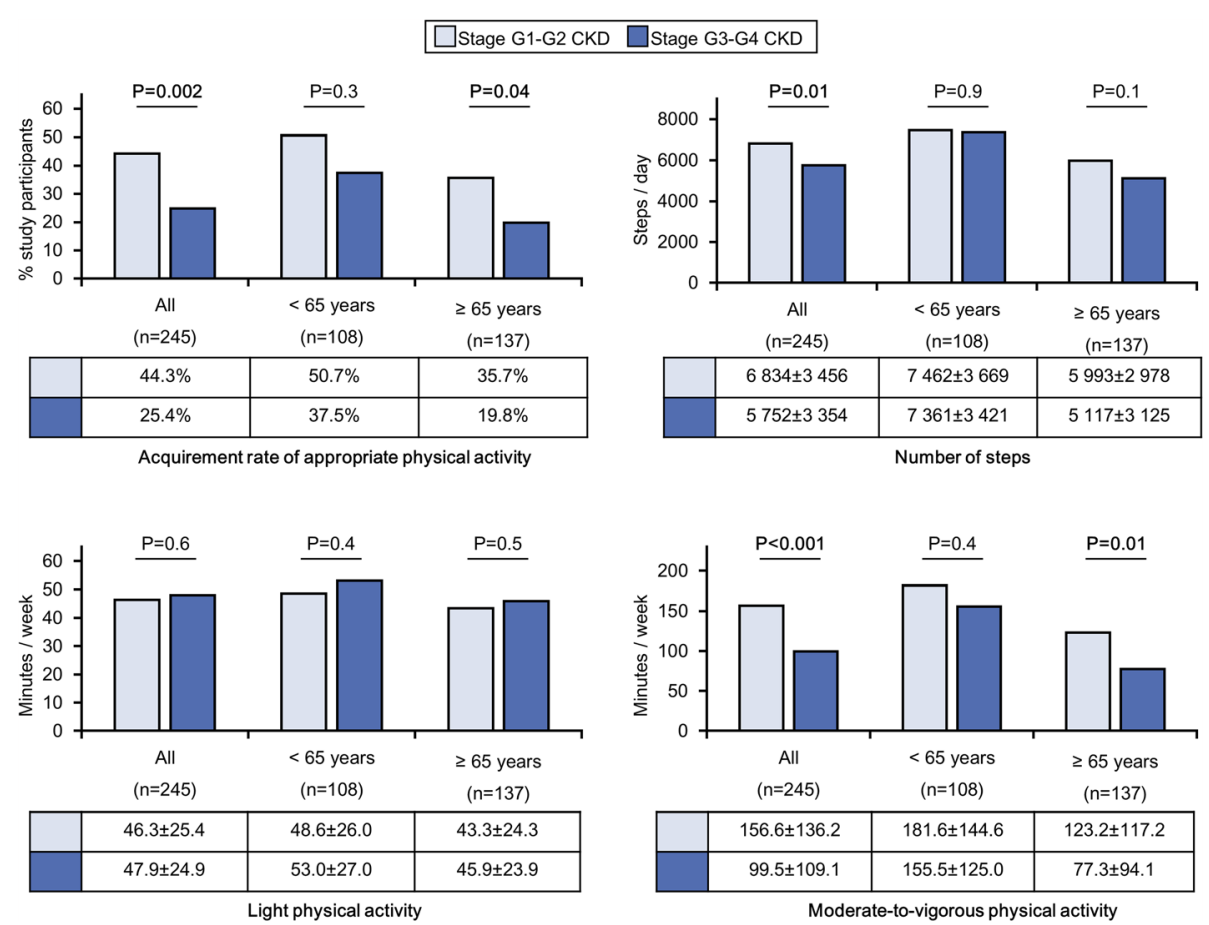

Fig. 1 Physical activity after hospital discharge in patients with ischemic heart disease

Table 2 The univariate and multivariate logistic regression analyses

\begin{tabular}{|c|c|c|c|c|c|}
\hline \multirow[b]{2}{*}{ Factors } & \multirow[b]{2}{*}{ Units of increase } & \multicolumn{2}{|c|}{ Univariate analysis } & \multicolumn{2}{|c|}{ Multivariate analysis } \\
\hline & & ORs $(95 \% \mathrm{Cl})$ & $P$ & ORs $(95 \% \mathrm{Cl})$ & $P$ \\
\hline CKD stage G3-G4 to stage G1-G2 & - & $2.33(1.35-4.01)$ & 0.002 & $1.91(1.02-3.55)$ & 0.04 \\
\hline Age & 10 years & $1.47(1.14-1.89)$ & 0.003 & - & - \\
\hline Women to men & - & $4.97(1.88-13.2)$ & 0.001 & - & - \\
\hline Body mass index & $1 \mathrm{~kg} / \mathrm{m}^{2}$ & $0.99(0.91-1.07)$ & 0.8 & - & - \\
\hline Unemployed to employed & - & $2.13(1.25-3.64)$ & 0.005 & - & - \\
\hline CABG to $P C l$ & - & $1.81(0.92-3.55)$ & 0.08 & - & - \\
\hline CVD to non-CVD & - & $2.65(0.87-8.09)$ & 0.09 & - & - \\
\hline Orthopedic disorder to non-orthopedic disorder & - & $1.21(0.60-2.43)$ & 0.6 & - & - \\
\hline DM to non-DM & - & $1.53(0.89-2.64)$ & 0.1 & - & - \\
\hline Ex-smoker to non-smoker & - & $0.56(0.28-1.11)$ & 0.1 & - & - \\
\hline Current smoker to non-smoker & - & $0.53(0.26-1.06)$ & 0.07 & - & - \\
\hline Hemoglobin & $1.0 \mathrm{~g} / \mathrm{dL}$ & $0.78(0.66-0.92)$ & 0.003 & - & - \\
\hline Albumin & $0.1 \mathrm{mg} / \mathrm{dL}$ & $0.94(0.88-0.99)$ & 0.04 & - & - \\
\hline High-sensitivity CRP & $0.1 \mathrm{mg} / \mathrm{dL}$ & $1.02(0.99-1.04)$ & 0.2 & - & - \\
\hline LVEF & $10 \%$ & $1.06(0.87-1.29)$ & 0.6 & - & - \\
\hline Duration of hospital stay & 1 day & $1.03(1.01-1.06)$ & 0.005 & - & - \\
\hline $6 \mathrm{MWD}$ of $<400 \mathrm{~m}$ to $6 \mathrm{MWD}$ of $\geq 400 \mathrm{~m}$ & - & $18.9(4.43-80.5)$ & $<0.001$ & $17.8(4.16-76.6)$ & $<0.001$ \\
\hline
\end{tabular}

Analyses were performed using univariate and multivariate logistic regression analyses

$O R$ s odds ratios, $C I$ confidence interval, $C K D$ chronic kidney disease, $C A B G$ coronary artery bypass grafting, CVD cerebrovascular disease, $D M$ diabetes mellitus, $C R P$ C-reactive protein, $L V E F$ left ventricular ejection fraction, 6MWD 6-min walk distance, $P C l$ percutaneous coronary intervention 
Table $\mathbf{3}$ Changes in renal function and exercise capacity

\begin{tabular}{llll}
\hline & $\begin{array}{l}\text { Stage G1-G2 } \\
\text { CKD } \\
(n=95)\end{array}$ & $\begin{array}{l}\text { Stage G3-G4 } \\
\text { CKD } \\
(n=87)\end{array}$ & $P^{a}$ \\
\hline $\begin{array}{l}\text { eGFR }\left(\mathrm{mL} / \mathrm{min} / 1.73 \mathrm{~m}^{2}\right) \\
\begin{array}{l}\text { At baseline (hospital } \\
\text { discharge) }\end{array}\end{array}$ & $75.8 \pm 13.1$ & $45.1 \pm 13.7$ & $<0.001$ \\
At 3 months & $73.3 \pm 13.1$ & $47.1 \pm 15.6$ & $<0.001$ \\
$\begin{array}{l}\left.\Delta \text { eGFR (mL/min/1.73 } \mathrm{m}^{2}\right) \\
\text { 6-min walk distance }(\mathrm{m})\end{array}$ & $-2.47 \pm 11.2$ & $2.02 \pm 13.5$ & 0.03 \\
$\begin{array}{l}\text { At baseline (hospital } \\
\text { discharge) }\end{array}$ & $477.9 \pm 99.8$ & $460.4 \pm 99.8$ & 0.2 \\
$\begin{array}{l}\text { At 3 months } \\
\Delta \text { 6-min walk distance }(\mathrm{m})\end{array}$ & $58.1 \pm 59.6$ & $34.8 \pm 63.5$ & 0.01 \\
\hline
\end{tabular}

Values are expressed as mean \pm standard deviation

CKD chronic kidney disease, eGFR estimated glomerular filtration rate

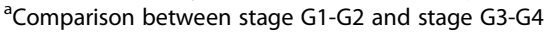

Maintaining a physically active lifestyle is therefore considered necessary for the secondary prevention of IHD after discharge in patients who also have CKD.

We found that stage G3-G4 CKD decreased moderate-to-vigorous physical activity after hospital discharge in patients with IHD. Many studies have reported that both patients on hemodialysis [20] and those with stage G3-G4 CKD have poor physical activity [7, 9, 10], supporting our findings. Three possible reasons may explain the relationship between CKD and physical inactivity. First, anemia is a frequent and inevitable complication of CKD that is detected even in early stages of CKD. Because anemia decreases oxygen delivery to skeletal muscles, patients with anemia might fatigue easily during moderate-to-vigorous physical activity, leading to their inactivity. Second, peripheral arterial disease is a major complication in patients with CKD. Some epidemiological studies have shown that the prevalence of peripheral arterial disease is significantly higher in nonhemodialytic patients with stage G3-G5 CKD than in patients with stage G1-G2 CKD [21, 22]. Ischemic symptoms such as muscle pain or lower extremity discomfort, which are induced by walking and remitted by rest, could hinder increasing physical activity in patients with stage G3-G4 CKD. Finally, depressive symptoms are known to attenuate the urge to leave the home, resulting in physical inactivity for CKD patients [23]. In a previous study surveying approximately 6000 communitydwelling elderly, patients with stage G3-G5 CKD had double the risk of depression compared to those with stage G1-G2 CKD [24]. On the basis of these reasons, stage G3-G4 CKD may hinder acquiring appropriate physical activity after discharge.

Goal-setting of physical activity is well known as one of the most popular techniques to promote in people with chronic illnesses $[25,26]$. A meta-analysis, which investigated the effectiveness of pedometer-used intervention on physical activity in community-dwelling people, concluded that setting a physical activity goal is a key motivational factor for increasing physical activity and is absolutely essential for successful intervention [27], and the same intervention successfully increased physical activity levels in CKD patients [28]. Chase JA et al. systematically reviewed what interventions were helpful in maintaining physical activity in cardiac patients, and suggested the self-monitoring with a pedometer, promoting during clinic visits, and objective feedback [29]. In addition to these approaches, we should promote for cardiac patients to participate in cardiac rehabilitation program more to rebuild selfconfidence to exercise.

There are some limitations to the present study. First, the study showed significant differences in age, the ratio of patients who were unemployed or had a smoking history, blood hemoglobin, left ventricular ejection fraction, and duration of hospital stay between patients with stage G1-G2 CKD and those with stage G3-G4 CKD. Therefore, we performed multivariate logistic regression analysis to assess the significant independent effects of stage G3-G4 CKD on physical activity. Consequently, stage G3-G4 CKD was identified as the significant independent factor in the present study. Second, although we considered the effect of clinical characteristics to the extent possible, an effect of albuminuria on physical activity in our patients was not elucidated. Albuminuria is a well-known symptom for CKD patients, and a recent study showed a positive correlation between with albuminuria and frailty or sarcopenia in community-dwelling people [30, 31]. Therefore, albuminuria could disrupt the acquirement of appropriate physical activity after hospital discharge among the patients with IHD. In addition, we will consider the prevalence of sarcopenia in patients with CKD. Sarcopenia would be associated with low physical activity and exercise tolerance and deterioration of renal function. Third, although an aggregated time $\geq 150 \mathrm{~min} /$ week at moderate-tovigorous intensity was defined as appropriate physical activity in our study according to AHA/ACC guideline, it would be still controversial whether engaging in the physical activity level for Japanese patients with IHD or CKD to have a role in secondary prevention. Fourth, because we studied patients who could be followed up for more than 3 months after hospital discharge, they likely also had better compliance with treatment than patients who dropped out of the study during the follow-up period. If the study included the dropout patients, physical activity after discharge may have been much lower. Although we showed that stage G3-G4 CKD prevented achievement of appropriate physical activity after discharge in patients with 
Table 4 Baseline characteristics and changes in renal function and exercise capacity between active and non-active participants

\begin{tabular}{|c|c|c|c|c|}
\hline & $\begin{array}{l}\text { All patients } \\
(n=182)\end{array}$ & $\begin{array}{l}\text { Active participants } \\
(n=18)\end{array}$ & $\begin{array}{l}\text { Non-active participants } \\
(n=164)\end{array}$ & $P$ \\
\hline Age (years) & $64.0 \pm 10.7$ & $66.2 \pm 9.8$ & $63.7 \pm 10.8$ & 0.35 \\
\hline Gender (\% male) & 85.2 & 83.3 & 85.4 & 0.73 \\
\hline Height (m) & $1.63 \pm 0.08$ & $1.64 \pm 0.09$ & $1.63 \pm 0.08$ & 0.58 \\
\hline Weight (kg) & $64.1 \pm 11.8$ & $65.9 \pm 14.4$ & $63.9 \pm 11.5$ & 0.51 \\
\hline Body mass index $\left(\mathrm{kg} / \mathrm{m}^{2}\right)$ & $23.9 \pm 3.4$ & $24.3 \pm 4.4$ & $23.9 \pm 3.2$ & 0.61 \\
\hline Unemployed (\%) & 47.8 & 61.1 & 46.3 & 0.32 \\
\hline Intervention for IHD & & & & 0.54 \\
\hline CABG (\%) & 20.3 & 11.1 & 21.3 & \\
\hline $\mathrm{PCl}(\%)$ & 79.7 & 88.9 & 78.7 & \\
\hline \multicolumn{5}{|l|}{ Comorbidities (\%) } \\
\hline Cerebrovascular disease & 8.8 & 11.1 & 8.5 & 0.66 \\
\hline Orthopedic disorder & 19.9 & 23.5 & 19.5 & 0.75 \\
\hline Diabetes mellitus & 40.1 & 38.9 & 40.2 & 1.00 \\
\hline Smoking (\%) & & & & 0.17 \\
\hline Current & 35.9 & 17.6 & 37.8 & \\
\hline Former & 35.4 & 53.0 & 33.5 & \\
\hline Never & 28.7 & 29.4 & 28.7 & \\
\hline \multicolumn{5}{|l|}{ Laboratory data } \\
\hline Hemoglobin (g/dL) & $12.9 \pm 1.64$ & $12.7 \pm 1.36$ & $13.0 \pm 1.70$ & 0.49 \\
\hline Peak creatine kinase (IU/L) & $2367 \pm 2536$ & $2719 \pm 3102$ & $2330 \pm 2479$ & 0.55 \\
\hline Albumin (g/dL) & $3.94 \pm 0.42$ & $3.91 \pm 0.45$ & $3.94 \pm 0.41$ & 0.74 \\
\hline High-sensitive CRP (mg/dL) & $0.76 \pm 1.24$ & $0.43 \pm 0.44$ & $0.79 \pm 1.29$ & 0.25 \\
\hline Left ventricular ejection fraction (\%) & $51.2 \pm 13.7$ & $50.0 \pm 13.9$ & $51.3 \pm 13.7$ & 0.70 \\
\hline Ankle-brachial index & $1.08 \pm 0.12$ & $1.09 \pm 0.14$ & $1.08 \pm 0.12$ & 0.65 \\
\hline Duration of hospital stay (days) & $25.9 \pm 16.4$ & $22.9 \pm 6.73$ & $26.3 \pm 17.1$ & 0.41 \\
\hline \multicolumn{5}{|l|}{ eGFR $\left(\mathrm{mL} / \mathrm{min} / 1.73 \mathrm{~m}^{2}\right)$} \\
\hline At baseline (hospital discharge) & $61.6 \pm 19.2$ & $58.8 \pm 20.6$ & $61.9 \pm 19.1$ & 0.52 \\
\hline At 3 months & $59.6 \pm 20.5$ & $61.8 \pm 17.2$ & $59.4 \pm 20.9$ & 0.68 \\
\hline$\Delta$ eGFR $\left(\mathrm{mL} / \mathrm{min} / 1.73 \mathrm{~m}^{2}\right)$ & $-0.97 \pm 13.9$ & $4.77 \pm 19.7$ & $-1.53 \pm 13.2$ & 0.12 \\
\hline \multicolumn{5}{|l|}{ 6-min walk distance $(\mathrm{m})$} \\
\hline At baseline (hospital discharge) & $469.5 \pm 99.8$ & $451.8 \pm 85.3$ & $471.5 \pm 101.3$ & 0.43 \\
\hline At 3 months & $516.5 \pm 110.2$ & $511.9 \pm 88.1$ & $517.0 \pm 112.6$ & 0.86 \\
\hline$\Delta$ 6-min walk distance $(\mathrm{m})$ & $46.9 \pm 62.4$ & $60.1 \pm 37.8$ & $45.5 \pm 64.5$ & 0.35 \\
\hline
\end{tabular}

Values are expressed as mean \pm standard deviation or percentage

$C A B G$ coronary artery bypass graft, $C K D$ chronic kidney disease, CRP C-reactive protein, eGFR estimated glomerular filtration rate, $I H D$ ischemic heart disease, $P C I$ percutaneous coronary intervention

IHD, the underlying mechanisms remain undetermined. We have previously reported that the frailty was detected in approximately half of patients with stage G5 CKD [32], in which the muscle weakness is observed in patients with not only stage G5 CKD but also stage G3-G4 CKD [33]. It is well known that muscle weakness is associated with lower physical activity in older adults. Therefore, further studies are needed to clarify the potential mechanisms underlying the association between CKD and decreased physical activity.

\section{Conclusions}

Stage G3-G4 CKD in patients with IHD was associated with poor acquirement of appropriate physical activity after hospital discharge. 


\section{Abbreviations}

ACC: American College of Cardiology; AHA: American Heart Association; CKD: Chronic kidney disease; eGFR: Estimated glomerular filtration rate; HD: Ischemic heart disease

\section{Acknowledgements}

We are grateful for the help of Chiharu Noda, Takami Iwamura, Mari Kawano, Akiko Igarashi, and other staffs in the cardiac rehabilitation room.

\section{Funding}

This research was supported by JSPS KAKENHI (Grant Number 26350585).

\section{Availability of data and materials}

We decided not to share the data in our study because the data are thoroughly described and reflected in the accompanying tables and figures (All relevant data are within the paper)

\section{Authors' contributions}

This article has eight authors. Our study needed a planner of the study (JA, TM, RM), three persons for the measurement $(\mathrm{NH}, \mathrm{KN}, \mathrm{ST})$, two persons as the study explainer (RM, KK), two persons for the data entry (RM, KK), two persons as analyst (TM, RM), and the head of research (TM). All authors read and approved the final version of the manuscript.

\section{Competing interests}

The authors declare that they have no competing interests.

\section{Consent for publication}

I consent to publish the entire text of my dissertation.

\section{Ethics approval and consent participate}

This study was approved by the Kitasato University Hospital Research Ethic Committee and was conducted in accordance with the standards set forth by the latest revision of the Declaration of Helsinki. All patients received a detailed explanation of the study protocol and provided informed consent.

\section{Publisher's Note}

Springer Nature remains neutral with regard to jurisdictional claims in published maps and institutional affiliations.

\section{Author details}

'Department of Rehabilitation, Kitasato University Hospital, Sagamihara, Japan. ${ }^{2}$ Department of Rehabilitation, School of Allied Health Sciences, Kitasato University, 1-15-1 Kitasato, Sagamihara, Kanagawa 252-0373, Japan. ${ }^{3}$ Department of Cardio-Angiology, Graduate School of Medical Sciences, Kitasato University, Sagamihara, Japan. ${ }^{4}$ Department of Cardiovascular Medicine, Kitasato University School of Medicine, Sagamihara, Japan.

Received: 12 October 2016 Accepted: 22 March 2017

Published online: 30 June 2017

\section{References}

1. Barengo NC, Hu G, Lakka TA, Pekkarinen H, Nissinen A, Tuomilehto J. Low physical activity as a predictor for total and cardiovascular disease mortality in middle-aged men and women in Finland. Eur Heart $J$. 2004;25(24):2204-11

2. Li J, Siegrist J. Physical activity and risk of cardiovascular disease-a metaanalysis of prospective cohort studies. Int J Environ Res Public Health. 2012; 9(2):391-407.

3. Nocon M, Hiemann T, Muller-Riemenschneider F, Thalau F, Roll S, Willich SN. Association of physical activity with all-cause and cardiovascular mortality: a systematic review and meta-analysis. Eur J Cardiovasc Prev Rehabil. 2008; 15(3):239-46.

4. Arnett DK. Wicked problems and worthy pursuits: resolving to meet American Heart Association 2020 Impact Goals. Circulation. 2012;125(21): 2554-6.

5. Eckel RH, Jakicic JM, Ard JD, de Jesus JM, Houston Miller N, Hubbard VS, et al. 2013 AHA/ACC guideline on lifestyle management to reduce cardiovascular risk: a report of the American College of Cardiology/ American Heart Association Task Force on Practice Guidelines. Circulation. 2014;129(25 Suppl 2):S76-99.
6. Stevenson TG, Riggin K, Nagelkirk PR, Hargens TA, Strath SJ, Kaminsky LA. Physical activity habits of cardiac patients participating in an early outpatient rehabilitation program. J Cardiopulm Rehabil Prev. 2009;29(5): 299-303.

7. Beddhu S, Baird BC, Zitterkoph J, Neilson J, Greene T. Physical activity and mortality in chronic kidney disease (NHANES III). Clin J Am Soc Nephrol. 2009:4(12):1901-6.

8. Robinson-Cohen C, Littman AJ, Duncan GE, Weiss NS, Sachs MC, Ruzinski J, et al. Physical activity and change in estimated GFR among persons with CKD. J Am Soc Nephrol. 2014;25(2):399-406.

9. Finkelstein J, Joshi A, Hise MK. Association of physical activity and renal function in subjects with and without metabolic syndrome: a review of the Third National Health and Nutrition Examination Survey (NHANES III). Am J Kidney Dis. 2006:48(3):372-82.

10. Navaneethan SD, Kirwan JP, Arrigain S, Schold JD. Adiposity measures, lean body mass, physical activity and mortality: NHANES 1999-2004 BMC Nephrol. 2014;15:108.

11. Laboratories ATSCOPSFCPF. ATS statement: guidelines for the six-minute walk test. Am J Respir Crit Care Med. 2002;166(1):111-7.

12. Morley JE, Abbatecola AM, Argiles JM, Baracos V, Bauer J, Bhasin S, et al. Sarcopenia with limited mobility: an international consensus. J Am Med Dir Assoc. 2011;12(6):403-9.

13. Schneider PL, Crouter SE, Lukajic O, Bassett Jr DR. Accuracy and reliability of 10 pedometers for measuring steps over a 400-m walk. Med Sci Sports Exerc. 2003;35(10):1779-84.

14. Kumahara H, Schutz $Y$, Ayabe M, Yoshioka M, Yoshitake $Y$, Shindo M, et al. The use of uniaxial accelerometry for the assessment of physical-activityrelated energy expenditure: a validation study against whole-body indirect calorimetry. Br J Nutr. 2004;91(2):235-43.

15. Takaya Y, Kumasaka R, Arakawa T, Ohara T, Nakanishi M, Noguchi T, et al. Impact of cardiac rehabilitation on renal function in patients with and without chronic kidney disease after acute myocardial infarction. Circ J. 2014;78(2):377-84

16. Matsuzawa R, Matsunaga A, Wang G, Kutsuna T, Ishii A, Abe Y, et al. Habitual physical activity measured by accelerometer and survival in maintenance hemodialysis patients. Clin J Am Soc Nephrol. 2012;7(12): 2010-6.

17. Wannamethee SG, Shaper AG, Walker M. Physical activity and mortality in older men with diagnosed coronary heart disease. Circulation. 2000;102(12): 1358-63.

18. Castaneda C, Gordon PL, Uhlin KL, Levey AS, Kehayias JJ, Dwyer JT, et al. Resistance training to counteract the catabolism of a low-protein diet in patients with chronic renal insufficiency. A randomized, controlled trial. Ann Intern Med. 2001;135(11):965-76.

19. Eidemak I, Haaber AB, Feldt-Rasmussen B, Kanstrup IL, Strandgaard S. Exercise training and the progression of chronic renal failure. Nephron. 1997:75(1):36-40.

20. Matsuzawa R, Matsunaga A, Kutsuna T, Ishii A, Abe Y, Yoneki K, et al. Association of habitual physical activity measured by an accelerometer with high-density lipoprotein cholesterol levels in maintenance hemodialysis patients. Sci World J. 2013;2013:780783.

21. Lash JP, Go AS, Appel LJ, He J, Ojo A, Rahman M, et al. Chronic Renal Insufficiency Cohort (CRIC) Study: baseline characteristics and associations with kidney function. Clin J Am Soc Nephrol. 2009;4(8): 1302-11.

22. Selvin E, Erlinger TP. Prevalence of and risk factors for peripheral arterial disease in the United States: results from the National Health and Nutrition Examination Survey, 1999-2000. Circulation. 2004;110(6): 738-43.

23. Zhang M, Kim JC, Li Y, Shapiro BB, Porszasz J, Bross R, et al. Relation between anxiety, depression, and physical activity and performance in maintenance hemodialysis patients. J Ren Nutr. 2014; 24(4):252-60

24. Campbell KH, Huang ES, Dale W, Parker MM, John PM, Young BA, et al. Association between estimated GFR, health-related quality of life, and depression among older adults with diabetes: the Diabetes and Aging Study. Am J Kidney Dis. 2013;62(3):541-8.

25. McEwan D, Harden SM, Zumbo BD, Sylvester BD, Kaulius M, Ruissen GR, et al. The effectiveness of multi-component goal setting interventions for changing physical activity behaviour: a systematic review and meta-analysis. Health Psychol Rev. 2016;10(1):67-88. 
26. O'Brien N, McDonald S, Araujo-Soares V, Lara J, Errington L, Godfrey A, et al. The features of interventions associated with long-term effectiveness of physical activity interventions in adults aged 55-70 years: a systematic review and meta-analysis. Health Psychol Rev. 2015;9(4):417-33.

27. Bravata DM, Smith-Spangler C, Sundaram V, Gienger AL, Lin N, Lewis R, et al. Using pedometers to increase physical activity and improve health: a systematic review. JAMA. 2007;298(19):2296-304.

28. Nowicki M, Murlikiewicz K, Jagodzinska M. Pedometers as a means to increase spontaneous physical activity in chronic hemodialysis patients. J Nephrol. 2010;23(3):297-305.

29. Chase JA. Systematic review of physical activity intervention studies after cardiac rehabilitation. J Cardiovasc Nurs. 2011;26(5):351-8.

30. Chang CC, Hsu CY, Chang TY, Huang PH, Liu LK, Chen LK, et al. Association between low-grade albuminuria and frailty among community-dwelling middle-aged and older people: a cross-sectional analysis from I-Lan Longitudinal Aging Study. Sci Rep. 2016;6:39434.

31. Kim TN, Lee EJ, Hong JW, Kim JM, Won JC, Kim MK, et al. Relationship between sarcopenia and albuminuria: the 2011 Korea National Health and Nutrition Examination Survey. Medicine (Baltimore). 2016;95(3), e2500.

32. Matsuzawa R, Matsunaga A, Wang G, Yamamoto S, Kutsuna T, Ishii A, et al. Relationship between lower extremity muscle strength and all-cause mortality in Japanese patients undergoing dialysis. Phys Ther. 2014;94(7): 947-56

33. Pereira RA, Cordeiro AC, Avesani CM, Carrero JJ, Lindholm B, Amparo FC, et al. Sarcopenia in chronic kidney disease on conservative therapy: prevalence and association with mortality. Nephrol Dial Transplant. 2015.

\section{Submit your next manuscript to BioMed Central} and we will help you at every step:

- We accept pre-submission inquiries

- Our selector tool helps you to find the most relevant journal

- We provide round the clock customer support

- Convenient online submission

- Thorough peer review

- Inclusion in PubMed and all major indexing services

- Maximum visibility for your research

Submit your manuscript at www.biomedcentral.com/submit 